\title{
The social gradient in preventive healthcare use: what can we learn from socially mobile individuals?
}

\section{Abstract}

Little is known about the origins of the stratified nature of preventive health behaviour. In this paper, we introduce theory and methodology from the field of social mobility research. Intergenerational, socially mobile individuals can provide insights into the central discussion about how health lifestyles or cultural health capital develop over the life course, during which different contexts of socialisation are encountered, each with its own characteristic health-related practices. We study the use of regular mammography screening by Belgian women using data from the Survey of Health, Aging and Retirement and we operationalise social mobility as occupational mobility using the International Standard Classification of Occupations (ISCO-88). By means of diagonal reference models, we are able to discern the effects of the social position of origin, the social position of destination and social mobility itself, contrary to the less rigorous linear regression approach that prevails in health behaviour research. As expected, the take up of mammography screening is strongly influenced by social position. It seems that both upwardly and downwardly mobile women adapt to the mammography screening practices in their position of destination. This study shows the potential for social mobility research to enrich the debate on health lifestyles.

Word count abstract: 197 words

Word count paper: 8365 (7 615+750 words for tables) 


\section{Introduction}

Departing from Weber's lifestyle concept (1978), Cockerham $(2005,2007)$ developed a 'health lifestyle theory' to underline the structural dimensions of health lifestyles. He described health lifestyles as "collective patterns of health-related behaviour based on choices from options available to people according to their life chances" (Cockerham 2000, p. 165). Health lifestyles are largely shared by individuals close to one another in the social space, and whose similar opportunities with regard to life chances give rise to a shared habitus as elaborated by Bourdieu in La Distinction (1984). In the same vein as Weber and Bourdieu, cultural health capital theory has recently been developed to explain persisting social inequalities in healthcare use. This field of research suggest that the social distribution of health-relevant knowledge and the skills used to lead healthy lives emanate from accumulation processes that start in childhood and proceed throughout the life course (Abel and Frohlich 2012; Mirowsky and Ross 2003; Missinne et al. 2013), "through repeated contacts with healthcare providers and lifelong socialization" (Shim 2010).

Little is known about how these accumulation processes of cultural health capital evolve. We are in the dark regarding whether and which specific life stages or experiences are crucial in the development of cultural health capital or health lifestyles (Singh-Manoux and Marmot 2005). Early life experiences seem important, as childhood socio-economic conditions shape the development of health-related behaviours (Kuh et al., 2004) when parents transfer skills and knowledge to their children (Abel and Frohlich 2012; Singh-Manoux and Marmot 2005). In addition to setting an example by buying food, (alcoholic) beverages, engaging in sport, taking their children for regular dental check-ups, etc., the beliefs supporting parents' own health behaviour are transmitted unintentionally or via explicit teaching efforts (Lau et al. 1990; Tinsley 2002). The childhood socio-economic environment has been empirically linked to several health behaviours in adulthood, such as smoking, alcohol consumption, diet, physical activity and dental service use (Gilman et al. 2003; Huurre et al. 2003; Lynch et al. 1997; Powe et al. 2005; Peres et al., 2007).

Socialisation into health behaviour continues throughout adult life, as proposed by health-related social control theory (Lewis and Butterfield 2007). Marital partners are considered the most important and powerful source of influence in a person's adult life (Umberson 1992), but other social network members, such as friends and offspring, can also become influential actors for health-related social 
control (Lewis and Butterfield 2007; Tucker 2002). With regard to health behaviour, life course researchers urge giving consideration to the dynamic nature of social ties (Thomas 2011; Umberson et al. 2010) and similarly, to social positions through each stage of the life course (e.g. Kuh et al. 2004; Lynch et al. 1997; Power et al. 2005; van de Mheen et al. 1998).

We believe that social mobility research can yield insights into the development of health behaviour, as socially mobile individuals have encountered different contexts of socialisation, each with its own characteristic levels of cultural (health) capital and health-related practices. We focus on intergenerational mobility, which refers to the change of position within the social hierarchy between parents and their children (Sorokin 1927). Studying the health behaviour of these individuals might help us to gain insight into the relative importance of a person's social position of origin compared with their social position of destination for the development of health behaviour.

Much uncertainty remains with regard to the issue of social mobility and health behaviour (Pollitt et al. 2005). Investigation into this topic is hampered by a longstanding methodological difficulty to simultaneously estimate the effects of social position of origin, social position of destination and social mobility. Since social mobility is linearly dependent on both the social position of origin and destination, the parameterization of the independent effect of origin, social position of destination and social mobility in a traditional regression framework is not possible (Hendrickx et al. 1993; Sobel 1981). Health behaviour research still largely draws on this linear regression approach (e. g. Bowes et al. 2013; Gall et al. 2010; Karvonen et al. 1999; Kuntz and Lampert 2013; Pearce et al. 2009; Peres et al., 2007; Silverwood et al., 2012; Watt et al. 2009), rendering conclusions very tentative.

We employ Sobel's (1981) diagonal reference model, which is considered to be "the only acceptable method to model mobility effects" (Houle 2011, p. 764). This technique allows us to disentangle the effects of social position of origin, social position of destination and the effect of transitioning between them. The theoretical starting point of this statistical technique is the idea that socially immobile individuals represent the core of each social stratum. For example, De Graaf et al. (1995, p. 1007) argue that the characteristic attitudes of a farmer can be best understood by going to those men who were "born and bred a farmer". Therefore the health-related behaviour of socially immobile individuals is considered characteristic for that social position. The estimates will be derived by comparing the health behaviour of socially mobile individuals to the health behaviour of the immobile individuals 
situated in the corresponding social position of origin and destination. Within the scope of this paper, we focus on mammography screening, which is the only current option for detecting breast cancer at an early stage (Palencia et al. 2010). It is the most frequently diagnosed form of cancer and the leading cause of death from cancer among women, with an estimated mortality rate of $16.7 \%$ (Ferlay et al. 2007; Jemal 2011; World Health Organization [WHO] 2013). Despite recommendations by the WHO (2013) and the European Union (OJ C 68E, 3 March 2004, pp. 611-17), not all women aged 5069 years engage in mammography screening and socio-economic inequalities in its use seem to persist in Europe, including Belgium (Jusot et al. 2012; Lorant et al. 2002; Puddu et al. 2009; Renard et al. 2014).

Because mammography screening is a relatively recent health practice and is only recommended between the ages of 50-69 years, not many women in our sample will have seen their mothers set an example. However, Cockerham (2007) highlighted that notwithstanding their own complexities, health practices comprise an overall pattern so that the regular take-up of preventive mammography screening can be viewed as an expression of a health lifestyle that started to develop during childhood. Bourdieu's notion of the habitus (1984) entails that "health-related behaviour can be seen as a largely routinized feature of everyday life which is guided by a practical or implicit logic" (Williams 1995, p. 583). Missinne et al. (2014) argue for a general behavioural orientation towards a health lifestyle (Donovan et al. 1993) by linking different forms of preventive health behaviours across the life course. Women whose parents took them for dental check-ups seem to be more likely to take up regular mammography screening in later life, irrespective from traditional measures of childhood and adulthood socio-economic factors and despite the efforts of the Belgian government to engage all women aged 50-69 in free mammography screening. In addition to that of the parents, the health lifestyle of the partner can affect individual's health behaviour. A follow-up study showed that also the partners' preventive health behaviour in childhood predicts the woman's regular mammography screening, independently from her own childhood preventive health behaviour and the aforementioned factors (Missinne et al. 2013).

Studying the example of mammography screening offers two important advantages. First, this type of preventive health behaviour is only recommended from the age of 50 onwards (WHO 2013), when social mobility processes are likely to have been actualised. Therefore, this form of health behaviour is 
unlikely to affect the course of social mobility. In most studies, such a process of reversed causality cannot be ruled out and hampers causal interpretations of the effect of social mobility (Claussen et al. 2005). Second, it is very unlikely that mammography screening is related to the event and accompanying stress of social mobility itself, as has been suggested for health-compromising behaviours such as alcohol use or dietary patterns (Karvonen et al. 1999).

\section{Theoretical expectations and hypotheses}

Social mobility constitutes a central topic in sociology (e.g. Blau and Duncan 1967; Ganzeboom et al. 1991; Lipset and Zetterberg 1956). In his pioneering work, Sorokin (1927) defined social mobility as the shifting of individuals within social space, and he claimed that socially mobile individuals exhibit distinctive attitudes and values as a result of the cross-fertilisation of attitudes and values originating from different social strata (Sorokin 1927). A large body of social inequality research focuses on social mobility to arrive at a better understanding of the stratification process, the openness of a society, its meritocratic character and other factors (e.g. the Wisconsin longitudinal study). Although related, our research questions pertain to the individual experience of social mobility and how it is expressed in everyday life, in the form of the health-related choices individuals make and the way these are socially structured. Our interest in socially mobile individuals departs from the fact that they have been socialised by two different social strata. It is plausible that both contexts of socialisation will manifest themselves in the behaviour of socially mobile individuals. However, hypotheses can be formulated as to which context has the predominant effect on the health behaviour of socially mobile individuals.

Traditional socialisation theory considers parental socialisation as deep and lasting, because children are believed to be much more malleable than adults (Brim 1968; Rosow 1974).People are imprinted with socialising messages during childhood; imprints which are deemed to continue to manifest themselves throughout the life course. According to Bourdieu $(1984,1990)$, lived experiences during childhood are crucial in the formation of the habitus. Viewing preventive mammography screening as a manifestation of positive health behaviour, this would lead us to expect the behaviour to be predominantly shaped by the primary socialisation context: the social position of origin. In line with research on social mobility effects (e.g. Tolsma et al. 2009), we term this the origin hypothesis. 
However, the depiction of socialisation in traditional theory has been criticised as being too unidirectional and too straightforward. Contemporary theory reframes socialisation as a group-to-group relationship, instead of a dyadic relationship between parent and child (e.g. Corsaro 2005; Harris 1995; Thorne 1993). Furthermore, it stresses that socialisation is never complete. Although parents are important socialising agents, socialisation continues into adulthood when individuals are confronted with new experiences (Ryder 1965) and other significant network members become important for health behaviours (Christakis and Fowler 2007, 2008). Accordingly, it has been suggested that the idea of a class-rigid and static habitus founded in childhood experiences no longer holds true (e.g. Daenekindt and Roose 2013b; Lahire 2011). In line with these arguments, we can formulate a contrasting hypothesis to the origin hypothesis - the destination hypothesis - which states that the health behaviour of socially mobile individuals will be predominantly associated with the social position of destination.

The destination and origin hypotheses implicitly depart from the assumption that upward and downward mobility are similar in their effects. This is not necessarily the case, as the experience of upward social mobility is quite different from that of downward social mobility. For example, the latter is often associated with feelings of failure (Blau 1956). In accordance with this line of thinking, the maximisation hypothesis has been proposed (De Graaf and Ganzeboom 1990). According to this, socially mobile individuals adapt to the highest status group. For upwardly mobile individuals this means that they would adapt to the lifestyle patterns of their newly achieved social position, while downwardly mobile individuals retain the lifestyle of their social position of origin. Monden and de Graaf (2012) reasoned that the former individuals reflect the more healthy lifestyle of their achieved social position, while the latter notice the negative health effects of the lifestyle of their new social group. In health research, this phenomenon, through which past social conditions protect against vulnerability, has also been termed 'social protection' (Heraclides and Brunner 2010).

\section{Data and methods}

\section{Data}


We use data from the Belgian sample of the Survey of Health, Ageing and Retirement (SHARE), which contains detailed information on health, healthcare use and socio-economic status, among other factors. All respondents aged 50 or over at the time of the interview, and their partners where available (and children older than 50 living with their parents), were interviewed face-to-face using structured, computerised questionnaires. In Belgium, households were selected based on multi-stage probability sampling (for details see Mannheim Research Institute for the Economics of Ageing [MEA] 2010). The first wave was carried out in 2004. In Belgium, household and individual response rates were $39.2 \%$ and $90.5 \%$ respectively (SHARE 2012). Information on the social position of destination was retrieved from this first wave. After a second wave of data collection (2006-2007), respondents were re-contacted for a third wave (SHARELIFE 2008-2009), which complemented the panel data with retrospective life histories. This third wave provides longitudinal information on the social position of origin and on mammography screening. Special efforts were made to reduce attrition and attain high retention rates (Blom and Schröder 2011). For our study, we exclude women older than 85 in 2004 (N $=17$ ), so that our observation period starts when the first initiatives for mammography screening were introduced (from 1989 to 1992 in the provinces of Antwerp and Limburg) (Van Oyen and Verellen 1994; Vlaams Agentschap Zorg en Gezondheid [VAZG] 2010). In addition, given our focus on preventive healthcare behaviour, women diagnosed with breast cancer during their lives are also excluded $(\mathrm{N}=34 ; 2.4 \%)$.

\section{Measurements}

\section{Independent variables: social position of origin and social position of}

\section{destination}

Similar to studies on social mobility and health-related behaviour (e.g. Karvonen et al. 1999; Pearce et al. 2009; Silverwood et al. 2012; Thomson et al. 2004), we operationalise social mobility as occupational mobility. Our focus on older women entails the need to consider carefully how homemakers are classified. A substantial number of the women had never worked during their lives, as their working age coincided with a period characterised by the male breadwinner model (Tilly and Scott 1987; Vanhautte 2002). To maximise the robustness of the findings, we test the hypotheses in two ways. First, we confine the sample to women who have been in the labour market at some time 
during their lives and we use their own occupational position. Second, we include all women in the sample and use the occupation of the husband instead. The reasoning behind this is the welldocumented tendency for social homogamy (Blackwell 1998; Kalmijn 1998; Smits et al. 2000) and the concordance of health behaviours between partners (Falba and Sindelar 2008).

The social position of origin is assessed by means of the occupational category of the main breadwinner when the respondent was ten years old. The occupational categories provided are the ten major groups of the International Standard Classification of Occupations (ISCO-88) developed by the International Labour Organization ${ }^{1}$ We use the same categories as Dumont (2006): i) white-collar high skilled; ii) white-collar low skilled; iii) blue-collar high skilled and iv) blue-collar low skilled, except that we exclude the very small number of armed forces personnel. Together with individuals who have missing information, this results in omitting 97 cases $(7.1 \%)$ from the first sample and 93 cases $(6.9 \%)$ from the second.

The social position of destination is derived from the 4-digit ISCO-88 codes generated by the SHARE team. The first digit, which refers to the previously mentioned major groups, is used to categorise the occupations in a similar manner to that used for the social position of origin. For the first set of analyses, we retrieve the information on women's own ISCO by means of the answers to "the exact name or title" of their main job or their last main job. The former applies to women who were still employed at the time of interview in 2004 , while the latter refers to women who stated they were retired, unemployed, permanently ill/disabled or homemakers. From the results, the occupational position of $18.3 \%$ women is classified as blue-collar low skilled, $7.8 \%$ blue-collar high skilled, $23.6 \%$ white-collar low skilled and $29.1 \%$ white-collar high skilled. Some $12.9 \%$ had a higher social position in 2004 than when they were children, while $52.8 \%$ were downwardly mobile (results not shown). In total, $21.1 \%$ of the women could not be included because information on occupational position was lacking, in most cases because they had never entered the labour market (14.6\%).

For the second sample, we make use of the dyadic nature of the SHARE. It is the male partner who reported the "exact name or title" of their main job or last main job. If the married or cohabiting partner was no longer alive or did not take part in the survey, his last occupation was reported by the partner

\footnotetext{
${ }^{1}$ The ten groups are: legislator, senior official or manager; professional; technician or associate professional; clerk; service, shop or market sales worker; skilled agricultural or fishery worker; craft or related trades worker; plant/machine operator or assembler; elementary occupation; and armed forces.
} 
through the question "What is the most recent job your [ex-/late] partner had?" The use of the partners' occupational position results lead us to categorise $15.4 \%$ of women as blue-collar low skilled, $19.3 \%$ blue-collar high skilled, $11.4 \%$ white-collar low skilled and $38.8 \%$ white-collar high skilled. Social mobility figures are similar here. Some $13.6 \%$ of the women had moved up the social latter while $32.2 \%$ had moved down (results not shown). In this sample, $15.6 \%$ of the cases had to be omitted, because of missing information on partners' occupational position (12\%) and because some women had never married (3.6\%). Tables 1 and 2 show the number of socially mobile individuals for both samples.

\section{Dependent variable: mammography screening}

We examine whether or not women had commenced regular mammography screening before 2004 . This time coincides with the data collection for the first wave, when the destination social position was appraised. We combine the information for the questions "Have you ever had mammograms regularly over the course of several years?" and "In which year did you start having mammograms regularly?" As it is recommended to have mammography screening every two years (European Commission 2003), women who started screening but did not continue it on a regular basis during the recommended age range (50 to 69 years old) are given a score of zero, together with those who never started screening. The majority of women had started mammography screening during their lives (63.2\% in the first sample and $59.2 \%$ in the second). Information on screening is lacking for only a small number of women and they are therefore deleted list-wise (respectively $3.2 \%$ and $3.1 \%$ ). Accordingly, the final sample consists of 963 women using the first sample and 1,015 women using the second.

\section{Covariates: age}

Risk factors for breast cancers are not well understood (Palencia, 2010), besides age and those associated with prolonged exposure to endogenous estrogens, such as late age at first childbirth and 
early menarche (Lacey et al. 2009) ${ }^{2}$. Women aged 50-69 are at the highest risk for breast cancer (Kohn, 2013) and therefore constitute the target group of national screening programs. In 2001, a population-based screening programme was implemented by the Belgian government, in which all women aged between 50 and 69 were offered free mammography screening every two years (VAZG 2010). We introduce a dichotomous variable in the models to control for the effect of public policy concerning mammography screening, as this has changed over time. Women who had been offered screening at least once (those born between 1931 and 1954) are compared with women who had not (those born before 1931).

\section{Statistical analysis}

To estimate the relative impact of social position of origin and of destination, we use Diagonal Reference Models (DRMs). DRMs were designed specifically to study the effects of social mobility. This method has been used in a wide variety of research fields, such as political behaviour, (e.g. Weakliem 1992), antagonistic attitudes (e.g. Tolsma et al. 2009) and cultural participation (e.g. Daenekindt and Roose 2013a, 2014; De Graaf 1991). They have also been applied in health research (e.g. Claussen et al. 2005; Monden and de Graaf 2012; Monden et al. 2003, Houle and Martin 2011, Houle 2011).

Central to this technique is the idea that immobile individuals represent the core of a specific social position. Consequently, the health behaviour of socially mobile individuals is modelled as a function of the characteristic behaviour of immobile individuals from the social position of origin and of destination. The baseline model (including age) is:

$$
Y_{i j k}=p * \mu_{i i}+(1-p) * \mu_{j j}\left(+\sum \beta_{b} x_{i j b}\right)+\varepsilon_{i j k}
$$

where $i$ refers to the social position of origin and $j$ to that of destination. $Y_{i j k}$ is the value of the dependent variable in cell $i j$, which has $k$ observations and represents the health-related behaviour of socially mobile individuals whose social position of origin is $i$ and of destination is $j . \mu_{i i}$ and $\mu_{j j}$ are both estimates of $Y$ in the diagonal cells. The relative importance of the social position of origin is represented by $p$. p-parameters significantly higher than .5 indicate that $Y$ is predominantly associated

\footnotetext{
${ }^{2}$ We do not include these risk factors in the analyses, since previous work has shown that they did not yield independent effects from socio-economic position parameters.
} 
with the social position of origin, which is in line with the origin hypothesis. Vice versa, $p$-parameters significantly lower than .5 indicate a stronger relationship with the social position of destination, therefore consistent with the destination hypothesis. The calculation of the DRMs is illustrated by figure 1.

(figure 1 about here)

The maximisation model is an extension of the baseline model and states that the health-related behaviour of socially mobile individuals is predominantly associated with the highest social position they have encountered, whether that of origin or of destination. To test the maximisation hypothesis, we construct a dummy $x_{i j m}$ : downwardly mobile individuals score 1 , upwardly mobile individuals score 0. The maximisation model can be expressed as:

$$
Y_{i j k}=\left(p+m x_{i j m}\right) * \mu_{i i}+\left(1-\left(p+m x_{i j m}\right)\right) * \mu_{j j}+\sum \beta_{b} x_{i j b}+\varepsilon_{i j k}
$$

(Model B)

For upwardly mobile individuals, the relative importance of the social position of origin is $p$. For downwardly mobile individuals, the relative importance of the social position of origin in this model is represented by ' $p+m$ '. Because our dependent variable is dichotomous, we apply a logistic regression model (Daenekindt and Roose 2013a). For example, Model A thus becomes as follows, where $\pi_{(x)}=$ $E(Y \mid x)$ is the conditional mean of $Y$, given $x$ :

$$
\pi_{(x)}=\frac{e^{p * \mu_{i i}+(1-p) * \mu_{j j}+\sum \beta_{b} x_{i j b}+\varepsilon_{i j k}}}{1+e^{p * \mu_{i i}+(1-p) * \mu_{j j}+\sum \beta_{b} x_{i j b}+\varepsilon_{i j k}}}
$$

\section{Results}

\section{Bivariate relations}

As could be expected and as illustrated in Table 1 and Table 2, mammography screening practices are stratified according to social position. The proportion who engaged in regular mammography screening is substantially higher among white-collar skilled women (76\% and $65 \%$ ) than blue-collar skilled women (45\% and 57\%). Based on the partners' ISCO-88 code, the figures are somewhat less pronounced (respectively $70 \%$ and $58 \%$ compared with $56 \%$ and $48 \%$ ). The diagonals of both Table 1 and Table 2 show that a similar social structuration of mammography screening can be found among 
the immobile individuals (the shaded boxes). Their screening behaviour is taken as the reference points in the DRM models.

(Table 1 and Table 2 around here)

\section{Diagonal Reference Models}

To test our hypotheses, we estimate the baseline and the maximisation model. For both models, we do this twice: once using the ISCO-88 of the respondent herself, and once for the operationalisation of social mobility where we use the ISCO-88 of the partner. Based on the Akaike Information Criterion (AIC), we see that the baseline model fits best in both instances (Table 3). We can therefore reject the maximisation hypothesis which stated that both upwardly and downwardly mobile individuals adapt to the screening behaviour of the highest status group. The effect of social mobility will thus be similar for both upwardly and downwardly mobile individuals.

\section{(Table 3 \& Table 4 around here)}

Now, we know that we should turn to the parameters of the baseline model to examine the origin and destination hypotheses (Table 4). Similar to the aforementioned descriptive statistics, the estimated means of the diagonals show the extent to which mammography screening is stratified. Immobile women with a higher social position have a higher probability of commencing regular mammography screening. For example, blue-collar low skilled women have much lower probability (.648) of screening than white-collar high skilled women do (.825). The same pattern is found in the general female population in which homemakers are included. The probabilities of screening are respectively .618 and .783 .

The weighting parameters - which are calculated based on the estimates of the immobile women- are the most interesting part of the analysis and will decide on the origin and destination hypothesis . In both cases - own ISCO-88 and partner's ISCO-88 - we see that screening is predominantly influenced by the social position of destination. By delineating a confidence interval around both $p$ parameters, it can be observed that both are significantly lower than .5 , thus providing evidence for the destination hypothesis. For example, the $95 \%$ confidence interval around .116 becomes [-.256; .488]. P-parameters significantly smaller than .5 indicate that the outcome variable - mammography screening - is predominantly guided by the social position of destination. The rejection of the maximisation hypothesis implies that the predominant influence of the social position of destination 
applies to both upwardly and downwardly mobile individuals. By means of the p-parameters and the values for the immobile women (shaded boxes), we can calculate the probabilities of mammography screening associated for all socially mobile women, according to the strategy outlined in figure 1 (see Table 5). Given the p-value of zero in the first sample, socially mobile women (off-diagonals) reflect the health behaviour of the immobile women (diagonals) exactly. In the second sample, the small pvalue leads to a very close reflection of the screening probabilities of socially mobile women to that of immobile women.

(Table 5 about here)

The effect of the control variable is in line with previous research (Missinne et al. 2013). Women who were not age eligible for the national screening programme have much lower probability in both samples of ever commencing regular screening $(0.078 ; 0.109)$.

\section{Discussion and conclusion}

Williams (2003) argues that a longitudinal approach is necessary to understand the role of social structure on health and health lifestyles (Williams 2003). We take a different approach to pioneering longitudinal studies on health that have concentrated on unraveling the direct and indirect long-term effects of childhood social position (Hayward and Gorman 2004; O'Rand and Hamil-Luker 2005). Instead, we argue that the health behaviour of socially mobile individuals can elucidate how cultural health capital and health lifestyles develop over the course of an individual's life. Within the scope of the present research question, these individuals are interesting with regard to shedding light on the underlying mechanisms of the social structuration of mammography screening that remain unexplained (Wübker 2012).

The retrospective longitudinal data of the SHARE allows to study regular mammography screening, which is a more clear expression of a health lifestyle. This notion of regularity is an important aspect of preventive health care but is often ignored in empirical research on socio-economic inequalities (Spadea et al. 2010). Also for mammography screening, its take up is only reported for a period of one 
or two years, which does not allow the study of its long-term use at the recommended regular intervals (European Commission 2003). Using a statistical technique which enables to accurately separate the effects of social position of origin, social position of destination and social mobility itself, we conclude that regular mammography screening is stratified according to women's occupational position in adulthood. Both upwardly and downwardly socially mobile individuals seem to largely adapt to the behavioural patterns of the social position of destination. Our results thus suggest that there is little room for imprints from childhood socialization into health behaviours. These results are in line with recent contentions that the habitus is less rigid than Bourdieu depicted and more adaptable to experiences other than those in childhood (Daenekindt and Roose 2013b; Lahire 2011). Indeed, also for health behaviours specifically, it has been argued that adult socialization is important (Lewis and Butterfield 2007).

However, concluding that childhood socio-economic environment does not matter at all for healthrelevant dispositions and for mammography screening in particular, would be jumping to conclusions. We could only use occupation to define a person's position in the social structure, as this is the only indicator for which we have information for both childhood and adulthood. Therefore, data limitations prevent us from considering other components of the social structure that might be crucial to the development of cultural health capital, such as educational level. This is regrettable given the strong association between educational level and preventive healthcare use, including mammography screening (Puddu et al. 2009; Stirbu et al. 2007; Missinne et al. 2014; Renard et al., 2014). Besides including the educational level of the parents, future research should apply a cross-national perspective, which would allow moving beyond 'controlling' for the supply effect of a population-based screening initiative as we have done here. National screening policies play an important role in mammography screening behaviour (Missinne \& Bracke, 2014), but the question remains of how these affect the relative impact of childhood and adult socialisation. Studying changes over time could also help to elucidate how adult socialisation is intertwined with social policy. Finally but most importantly, other forms of health behaviour of socially mobile individuals should be considered in order to shed light on the impact of the underlying general health lifestyle relative to the unique component of mammography screening practices (cfr. Wickrama 1999; Cockerham 2007). 
We have already mentioned that data limitations prevent us from considering other components of the social structure. Additional limitations should also be acknowledged. Information is only available for two time points and is lacking with regard to the age at which individuals moved up or down the social ladder. There might be different effects of social mobility according to the amount of time spent in the different social positions (Bartley and Plewis 2007), as proposed by cumulative exposure models (Willson et al. 2007). Finally, the example of mammography screening confines us to women. Studying other forms of health behaviour would allow us to examine whether the same processes apply to men, as masculinity beliefs have already been shown to be moderating factors for preventive healthcare use (Springer and Mouzon 2011).

In sum, studying the health behaviour of socially mobile women, we learn that mammography screening is predominantly shaped by their adulthood social position. Question is whether similar findings will result when using other indicators of social position. These and similar research questions about the social origins of health lifestyles, can benefit from an integration of the life course perspective and social mobility research. 


\section{References}

Abel, T. (2007) Cultural Capital in Health Promotion. In McQueen D.V., Kickbusch I., Potvin L., Pelikan J.M., Balbo L. and Abel T. (eds.) Health and Modernity: the Role of Theory in Health Promotion (pp. 43-73). New York: Springer.

Abel, T. (2008) Cultural capital and social inequality in health. Journal of Epidemiology and Community Health, 62(7).

Abel, T. and Frohlich, K.L. (2012) Capitals and capabilities: Linking structure and agency to reduce health inequalities. Social Science \& Medicine, 74, 236-244.

Bartley, M. and Plewis, I. (2007) Increasing social mobility: an effective policy to reduce health inequalities. Journal of the Royal Statistical Society (Series A) Statistics in Society, 170, 469481.

Blackwell, D.L. (1998) Marital homogamy in the United States: the influence of individual and paternal education. Social Science Research, 27(2), 159-188.

Blau, P. and Duncan, O. (1967) The American Occupational Structure. New York: Wiley.

Blau, P.M. (1956). Social-Mobility and Interpersonal-Relations. American Sociological Review, 21(3), 290-295.

Blom, A.G. and Schröder, M. (2011) Sample Composition 4 Years on: Retention in SHARE Wave 3. In Schröder M. (ed.) Retrospective Data Collection in the Survey of Health, Ageing and Retirement in Europe SHARELIFE Methodology (pp. 55-61). Mannheim: MEA.

Bourdieu, P. (1984) Distinction-A social critique of the judgement of taste. New York: Routledge.

Bourdieu, P. (1986) The Forms of Capital. In Richardson J. (ed.), Handbook of Theory and Research for the Sociology of Education (pp. 241-58). New York: Greenwood.

Bourdieu, P. (1990) The Logic of Practice. Stanford, California: Stanford University Press.

Bowes, L., Chollet, A., Fombonne, E., Galera, C. and Melchior, M. (2013) Lifecourse SEP and tobacco and cannabis use. European Journal of Public Health, 23(2), 322-327.

Brim, O. (1968) Adult Socialization. In Clausen J. (ed.), Socialization and Society (pp. 183-226). Boston: Little Brown.

Christakis, N. A. and Fowler, J.H. (2007) The spread of obesity in a large social network over 32 years. New England Journal of Medicine, 357(4), 370-379. 
Christakis, N.A. and Fowler, J.H. (2008) The collective dynamics of smoking in a large social network. New England Journal of Medicine, 358(21), 2249-2258.

Claussen, B., Smits, J., Naess, O. and Smith, G.D. (2005) Intragenerational mobility and mortality in Oslo: Social selection versus social causation. Social Science \& Medicine, 61(12), 2513-2520.

Cockerham, W.C. (2000) The Sociology of Health Behavior and Health Lifestyles. In Bird C.E., Conrad P. and Fremont A.M. (eds.) Handbook of Medical Sociology (pp. 159-72). Upper Saddle River, New Jersey: Prentice-Hall.

Cockerham, W.C. (2005) Health lifestyle theory and the convergence of agency and structure. Journal of Health and Social Behavior, 46(1), 51-67.

Cockerham, W.C. (2007) Social Causes of Health and Disease. Cambridge: Polity Press.

Corsaro, W. (2005) The Sociology of Childhood, Second Edition. Thousand Oaks: Pine Forge Press.

Daenekindt, S. and Roose, H. (2013a) Cultural Chameleons: Social Mobility and Cultural Practices in Private and Public Sphere. Acta Sociologica. 56 (4), 309-324.

Daenekindt, S. and Roose, H. (2013b) A Mise-en-scene of the Shattered Habitus: The Effect of Social Mobility on Aesthetic Dispositions Towards Films. European Sociological Review, 29(1), 4859.

Daenekindt, S. and Roose, H. (2014) Social mobility mobility and cultural dissonance. Poetics, 42, 8297. DOI 10.1016/j.poetic.2013.11.002

De Graaf, N. (1991) Distinction by consumption in Czechoslovakia, Hungary, and the Netherlands. European Sociological Review, 7(3), 267-290.

De Graaf, N.D. and Ganzeboom, H.B.G. (1990) Cultuurdeelname en opleiding: Een analyse van status-groep-effecten met diagonale referentiemodellen. Mens en Maatschappij, 65, 219-244.

De Graaf, N. D., Nieuwbeerta, P., \& Heath, A. (1995). Class mobility and political preferences: individual and contextual effects. American Journal of Sociology, 997-1027.

Donovan, J.E., Jessor, R. and Costa, F.M. (1993) Structure of Health-Enhancing Behavior in Adolescence - a Latent-Variable Approach. Journal of Health and Social Behavior, 34(4), 346362.

Dumont, M. (2006) The reliability-or lack thereof-of data on skills. Economics Letters, 93(3), 348-353.

European Commission. (2003) Council recommendations on cancer screening. http://ec.europa.eu. Accessed on 21 April 2013. 
Falba, T.A. and Sindelar, J.L. (2008) Spousal concordance in health behavior change. Health Services Research, 43(1), 96-116.

Ferlay, J., Autier, P., Boniol, M., Heanue, M., Colombet, M. and Boyle, P. (2007) Estimates of the cancer incidence and mortality in Europe in 2006. Annals of Oncology, 18(3), 581-592.

Gall, S.L., Abbott-Chapman, J., Patton, G.C., Dwyer, T. and Venn, A. (2010) Intergenerational educational mobility is associated with cardiovascular disease risk behaviours in a cohort of young Australian adults: The Childhood Determinants of Adult Health (CDAH) Study. BMC Public Health, 10, 55.

Ganzeboom, H.B.G., Treiman, D.J. and Ultee, W.C. (1991) Comparative Intergenerational Stratification Research - 3 Generations and Beyond. Annual Review of Sociology, 17, 277302.

Gilman, S.E., Abrams, D.B. and Buka, S.L. (2003) Socioeconomic status over the life course and stages of cigarette use: initiation, regular use, and cessation. Journal of Epidemiology and Community Health, 57(10), 802-808.

Harris, J.R. (1995) Where Is the Child's Environment - a Group Socialization Theory of Development. Psychological Review, 102(3), 458-489.

Hayward, M.D. and Gorman, B.K. (2004) The long arm of childhood: The influence of early-life social conditions on men's mortality. Demography, 41(1), 87-107.

Hendrickx, J., De Graaf, N.D., Lammers, J. and Ultee, W. (1993) Models for status inconsistency and mobility: A comparison of the approaches by Hope and Sobel with the mainstream square additive model. Quality and Quantity, 27(4), 335-352.

Heraclides, A. and Brunner, E. (2010) Social mobility and social accumulation across the life course in relation to adult overweight and obesity: the Whitehall II study. Journal of Epidemiology \& Community Health, 64(8), 714-719.

Houle, J.N. (2011) The psychological impact of intragenerational social class mobility. Social Science Research, 40(3), 757-772.

Houle, J.N. and Martin, M.A. (2011) Does intergenerational mobility shape psychological distress? Sorokin revisited. Research in Social Stratification and Mobility, 29(2), 193-203. 
Huurre, T., Aro, H. and Rahkonen, O. (2003) Well-being and health behaviour by parental socioeconomic status - A follow-up study of adolescents aged 16 until age 32 years. Social Psychiatry and Psychiatric Epidemiology, 38(5), 249-255.

Jemal, A. (2011) Global Cancer Statistics CA: a Cancer Journal for Clinicians, 61(2), 69-90. DOI: 10.3322/Caac.20115

Jusot, J.F., Or, Z. and Sirven, N. (2012) Variations in preventive care utilisation in Europe. European Journal of Ageing, 9 (1), pp. 15-25

Kalmijn, M. (1998) Intermarriage and homogamy: Causes, patterns, trends. Annual Review of Sociology, 24, 395-421. DOI: 10.1146/annurev.soc.24.1.395

Karvonen, S., Rimpela, A.H. and Rimpela, M.K. (1999) Social mobility and health related behaviours in young people. Journal of Epidemiol Community Health, 53(4), 211-217.

Kuh, D., Power, C., Blane, D. and Bartley, M. (2004) Socioeconomic pathways between childhood and adult health. In Kuh D.and Ben Shlomo Y. (eds.) A life course approach to chronic disease epidemiology (pp. 371-395). Oxford: Oxford University Press.

Kuntz, B. and Lampert, T. (2013) Intergenerational educational mobility and obesity in adolescence: findings from the cross-sectional German KiGGS study. Journal of Public Health, 21, 49-56.

Lacey, J.V., et al., (2009). Breast cancer epidemiology according to recognized breast cancer risk factors in the Prostate, Lung, Colorectal and Ovarian (PLCO) Cancer Screening Trial Cohort. Bmc Cancer, 9: 84.

Lahire, B. (2011). The Plural Actor. Cambridge: Polity Press.

Lau, R.R., Quadrel, M.J. and Hartman, K.A. (1990) Development and Change of Young-Adults Preventive Health Beliefs and Behavior - Influence from Parents and Peers. Journal of Health and Social Behavior, 31(3), 240-259.

Lewis, M.A. and Rook, K.S. (1999) Social control in personal relationships: Impact on health behaviors and psychological distress. Health Psychology, 18(1), 63-71.

Lipset, S. and Zetterberg, H. (1956) A theory of social mobility. Transactions of the Third World Congress of Sociology, 2, 155-177.

Lorant, V., Boland, B., Humblet, P. and Deliege, D. (2002) Equity in prevention and health care. Journal of Epidemiology and Community Health, 56(7), 510-516. 
Lynch, J.W., Kaplan, G.A. and Salonen, J.T. (1997) Why do poor people behave poorly? Variation in adult health behaviours and psychosocial characteristics by stages of the socioeconomic lifecourse. Social Science \& Medicine, 44(6), 809-819.

Mannheim Research Institute for the Economics of Ageing (2010) SHARELIFE release guide 1. Mannheim: MEA.

Mirowsky, J. and Ross, C.E. (2003) Education, social status, and health. New York: de Gruyter, Inc. Missinne, S., Colman, E. and Bracke, P. (2013) Spousal influence on mammography screening: a life course perspective. Social Science \& Medicine, 98, 63-70.

Missinne, S., Neels, K. and Bracke, P. (2014) Reconsidering inequalities in preventive health care: an application of cultural health capital theory and the life-course perspective. Sociology of Health \& IIIness, in press.

Missinne, S. \& Bracke, P. (2014). Age differences in mammography screening reconsidered: life course trajectories in 13 European countries. European Journal of Public Health, in press.

Monden, C.W. and de Graaf, N.D. (2012) The importance of father's and own education for selfassessed health across Europe: an East-West divide? Sociology of Health and IIIness.

Monden, C.W.S., van Lenthe, F., De Graaf, N.D. and Kraaykamp, G. (2003) Partner's and own education: does who you live with matter for self-assessed health, smoking and excessive alcohol consumption? Social Science \& Medicine, 57(10), 1901-1912.

O'Rand, A.M. and Hamil-Luker, J. (2005) Processes of cumulative adversity: Childhood disadvantage and increased risk of heart attack across the life course. Journals of Gerontology Series BPsychological Sciences and Social Sciences, 60, 117-124.

Palencia, L., Espelt, A., Rodriguez-Sanz, M., Puigpinos, R., Pons-Vigues, M., Pasarin, M.I., . . Borrell, C. (2010) Socio-economic inequalities in breast and cervical cancer screening practices in Europe: influence of the type of screening program. International Journal of Epidemiology, 39(3), 757-765.

Pampel, F.C. (2006) Socioeconomic distinction, cultural tastes, and cigarette smoking. Social Science Quarterly, 87(1), 19-35.

Pampel, F.C. (2012) Does reading keep you thin? Leisure activities, cultural tastes, and body weight in comparative perspective. Sociology of Health \& IIIness, 34(3), 396-411. 
Pearce, M.S., Thomson, W.M., Walls, A.W.G. and Steele, J.G. (2009) Lifecourse Socio-economic Mobility and Oral Health in Middle Age. Journal of Dental Research, 88(10), 938-941.

Peres, M.A., Peres, K.G., de Barros, A.J.D. and Victora, C.G. (2007) The relation between family socioeconomic trajectories from childhood to adolescence and dental caries and associated oral behaviours. Journal of Epidemiology and Community Health, 61(2), 141-145.

Pollitt, R.A., Rose, K.M. and Kaufman, J.S. (2005) Evaluating the evidence for models of life course socioeconomic factors and cardiovascular outcomes: a systematic review. BMC Public Health, $5,7$.

Power, C., Graham, H., Due, P., Hallqvist, J., Joung, I., Kuh, D. and Lynch, J. (2005) The contribution of childhood and adult socioeconomic position to adult obesity and smoking behaviour: an international comparison. International Journal of Epidemiology, 34(2), 335-344.

Puddu, M., Demarest, S. and Tafforeau, J. (2009) Does a national screening programme reduce socioeconomic inequalities in mammography use? International Journal of Public Health, 54(2), 61-68.

Renard, F., Demarest, S., Van Oyen, H. and Tafforeau, J. (2014) Using multiple measures to assess changes in social inequalities for breast cancer screening. European Journal of Public Health, 24(2), 275-280.

Rosow, I. (1974) Socialization to Old Age. Berkeley: University of California Press.

Ryder, N.B. (1965) The Cohort as a Concept in the Study of Social-Change. American Sociological Review, 30(6), 843-861.

SHARE. (2012) Survey of Health Ageing and Retirement. www.share-project.org.

Shim, J.K. (2010) Cultural Health Capital: A Theoretical Approach to Understanding Health Care Interactions and the Dynamics of Unequal Treatment. Journal of Health and Social Behavior, $51(1), 1-15$

Silverwood, R.J., Pierce, M., Nitsch, D., Mishra, G.D. and Kuh, D. (2012) Is Intergenerational Social Mobility Related to the Type and Amount of Physical Activity in Mid-Adulthood? Results from the 1946 British Birth Cohort Study. Annals of Epidemiology, 22(7), 487-498.

Singh-Manoux, A. and Marmot, M. (2005) Role of socialization in explaining social inequalities in health. Social Science \& Medicine, 60(9), 2129-2133. 
Smits, J., Ultee, W. and Lammers, J. (2000) More or less educational homogamy? A test of different versions of modernization theory using cross-temporal evidence for 60 countries. American Sociological Review, 65(5), 781-788.

Sobel, M.E. (1981) Diagonal Mobility Models - a Substantively Motivated Class of Designs for the Analysis of Mobility Effects. American Sociological Review, 46(6), 893-906.

Sorokin, P.A. (1927) Social Mobility. New York: Harper and Brothers.

Spadea, T., S. Bellini, A. Kunst, I. Stirbu, and G. Costa. 2010. The impact of interventions to improve attendance in female cancer screening among lower socioeconomic groups: A review. Preventive Medicine 50:159-164.

Springer, K.W. and Mouzon, D.M. (2011) "Macho Men" and Preventive Health Care: Implications for Older Men in Different Social Classes. Journal of Health and Social Behavior, 52(2), 212-227.

Stirbu, I., Kunst, A., Mielck, A. and Mackenbach, J.P. (2007) Educational inequalities in utilization of preventive services among elderly in Europe. Tackling Inequalities in Europe: An integrated approach. (pp. 483-99). Rotterdam Department of Public Health.

Thomas, P.A. (2011) Trajectories of Social Engagement and Limitations in Late Life. Journal of Health and Social Behavior, 52(4), 430-443.

Thomson, W.M., Poulton, R., Milne, B.J., Caspi, A., Broughton, J.R., and Ayers, K.M.S. (2004) Socioeconomic inequalities in oral health in childhood and adulthood in a birth cohort. Community Dentistry and Oral Epidemiology, 32(5), 345-353.

Thorne, B. (1993) Gender Play: Girls and Boys in School. Buckingham: Open University Press.

Tilly, L.A. and Scott, J.W. (1987) Women work and family. London: Routledge.

Tinsley, B.J., Markey, C.N., Ericksen, A.J., Ortiz, R.V. and Kwasman, A. (2002) Health Promotion for Parents. In Bornstein M.H. (ed.) Handbook of Parenting: Practical Issues in Parenting (Vol. 5, pp. 311-28). London: Lawrence Erlbaum Associates, publishers.

Tolsma, J., de Graaf, N.D. and Quillian, L. (2009) Does intergenerational social mobility affect antagonistic attitudes towards ethnic minorities? British Journal of Sociology, 60(2), 257-277.

Tucker, J.S. (2002) Health-related social control within older adults' relationships. Journals of Gerontology Series B-Psychological Sciences and Social Sciences, 57(5), 387-395.

Umberson, D. (1992) Gender, Marital-Status and the Social-Control of Health Behavior. Social Science \& Medicine, 34(8), 907-917. 
Umberson, D., Crosnoe, R. and Reczek, C. (2010) Social Relationships and Health Behavior Across the Life Course. Annual Review of Sociology, Vol 36, 36, 139-157.

van de Mheen, H., Stronks, K., Looman, C.W.N. and Mackenbach, J.P. (1998) Does childhood socioeconomic status influence adult health through behavioural factors? International Journal of Epidemiology, 27(3), 431-437.

Vanhautte, E. (2002) Breadwinner models and historical models. Transitions in labour relations and labour markets in Belgium, 19th-20th centuries. In Jensen H. (ed.) The welfare state. Past, present, future (pp. 59-76). Pisa: Edizione Plus.

Van Oyen, H. and Verellen, W. (1994) Breast cancer screening in the Flemish region, Belgium. European Journal of Cancer Prevention, 3, 7-12.

VAZG. (2010) Draaiboek Vlaams bevolkingsonderzoek naar borstkanker. Vlaams Agentschap Zorg en Gezondheid.

Watt, H.C., Carson, C., Lawlor, D.A., Patel, R. and Ebrahim, S. (2009) Influence of life course socioeconomic position on older women's health behaviors: findings from the British Women's Heart and Health Study. American Journal of Public Health, 99(2), 320-327.

Weakliem, D.L. (1992) Does social mobility affect political behaviour? European Sociological Review, 8, 153-165.

Weber, M. ([1922] 1978) Economy and Society (Vol. 1). Berkeley, California: University of California Press.

World Health Organization (2013) Breast cancer: prevention and control. http://www.who.int/cancer/detection/breastcancer/en/. Accessed on 20 April 2013

Wickrama, K.A.S., Conger, R.D., Wallace, L.E. and Elder, G.H. (1999) The intergenerational transmission of health-risk behaviors: Adolescent lifestyles and gender moderating effects. Journal of Health and Social Behavior, 40(3), 258-272.

Williams, S.J. (1995) Theorizing Class, Health and Life-Styles - Can Bourdieu Help Us. Sociology of Health \& IIIness, 17(5), 577-604.

Williams, G.H. (2003) The determinants of health: structure, context and agency. Sociology of Health \& IIIness, 25, 131-154.

Willson, A.E., Shuey, K.M. and Elder, G.H. (2007) Cumulative Advantage Processes as Mechanisms of Inequality in Life Course Health. American Journal of Sociology, 112(6), 1886-1924. 
Accepted to Sociology of Health and IIIness, on 15th October, 2014

Wübker, A. (2012) Who gets a mammogram amongst European women aged 50-69 years? Health Economics Review, 2(1). 


\section{Tables \& Figures}

Figure 1: Visual representation of the DRM method

\begin{tabular}{|c|c|c|c|c|}
\hline & Destination & & & \\
\hline Origin & 1 & 2 & 3 & 4 \\
\hline 1 & $\mu 11$ & $\left(p^{*} \mu 11\right)+\left((1-p)^{*} \mu 22\right)$ & $\left(p^{*} \mu 11\right)+\left((1-p)^{*} \mu 33\right)$ & $\left(p^{*} \mu 11\right)+\left((1-p)^{*} \mu 44\right)$ \\
\hline 2 & $\left(p^{*} \mu 22\right)+\left((1-p)^{\star} \mu 11\right)$ & $\mu 22$ & $\left(p^{*} \mu 22\right)+\left((1-p)^{*} \mu 33\right)$ & $\left(p^{*} \mu 22\right)+\left((1-p)^{*} \mu 44\right)$ \\
\hline 3 & $\left(p^{*} \mu 33\right)+\left((1-p)^{*} \mu 11\right)$ & $\left(p^{*} \mu 33\right)+\left((1-p)^{*} \mu 22\right)$ & $\mu 33$ & $\left(p^{*} \mu 33\right)+\left((1-p)^{*} \mu 44\right)$ \\
\hline 4 & $\left(p^{\star} \mu 44\right)+\left((1-p)^{\star} \mu 11\right)$ & $\left(p^{\star} \mu 44\right)+\left((1-p)^{\star} \mu 22\right)$ & $\left(p^{*} \mu 44\right)+\left((1-p)^{*} \mu 33\right)$ & $\mu 44$ \\
\hline
\end{tabular}

Table 1: Intergenerational mobility of women in Belgium who had ever been employed, percentage of women engaging in mammography screening in parentheses

\begin{tabular}{|c|c|c|c|c|c|c|c|c|c|c|}
\hline \multirow{3}{*}{$\begin{array}{l}\text { Origin } \\
\text { Blue-collar low skilled }\end{array}$} & \multicolumn{10}{|c|}{ Destination: own ISCO-88 of main or last main job } \\
\hline & \multicolumn{2}{|c|}{ Blue-collar low skilled } & \multicolumn{2}{|c|}{$\begin{array}{l}\text { Blue-collar } \\
\text { high skilled }\end{array}$} & \multicolumn{2}{|c|}{$\begin{array}{l}\text { White-collar } \\
\text { low skilled }\end{array}$} & \multicolumn{2}{|c|}{$\begin{array}{l}\text { White-collar } \\
\text { high skilled }\end{array}$} & \multicolumn{2}{|c|}{ Total } \\
\hline & 138 & $(59 \%)$ & 38 & $(42 \%)$ & 114 & $(67 \%)$ & 97 & $(75 \%)$ & 387 & (64\%) \\
\hline Blue-collar high skilled & 60 & $(60 \%)$ & 54 & $(46 \%)$ & 85 & $(66 \%)$ & 119 & $(82 \%)$ & 318 & $(68 \%)$ \\
\hline White-collar low skilled & 8 & $(25 \%)$ & 4 & $(50 \%)$ & 50 & $(60 \%)$ & 58 & $(76 \%)$ & 120 & $(65 \%)$ \\
\hline White-collar high skilled & 8 & $(25 \%)$ & 2 & $(50 \%)$ & 44 & $(66 \%)$ & 84 & $(69 \%)$ & 138 & $(65 \%)$ \\
\hline Total & 214 & $(57 \%)$ & 98 & $(45 \%)$ & 293 & $(65 \%)$ & 358 & $(76 \%)$ & 963 & $(65 \%)$ \\
\hline
\end{tabular}

Table 2: Intergenerational mobility of Belgian women, using the social position of the partner, percentage of women engaging in mammography screening in parentheses

\begin{tabular}{|c|c|c|c|c|c|c|c|c|c|c|}
\hline \multirow{3}{*}{$\begin{array}{l}\text { Origin } \\
\text { Blue-collar low skilled }\end{array}$} & \multicolumn{10}{|c|}{ Destination: partner's ISCO-88 of main or last main job } \\
\hline & \multicolumn{2}{|c|}{ Blue-collar low skilled } & \multicolumn{2}{|c|}{$\begin{array}{l}\text { Blue-collar } \\
\text { high skilled }\end{array}$} & \multicolumn{2}{|c|}{$\begin{array}{c}\text { White-collar } \\
\text { low skilled }\end{array}$} & \multicolumn{2}{|c|}{$\begin{array}{l}\text { White-collar } \\
\text { high skilled }\end{array}$} & \multicolumn{2}{|c|}{ Total } \\
\hline & 92 & $(57 \%)$ & 84 & $(43 \%)$ & 58 & $(55 \%)$ & 159 & $(70 \%)$ & 393 & $(59 \%)$ \\
\hline Blue-collar high skilled & 64 & $(55 \%)$ & 106 & $(50 \%)$ & 38 & $(58 \%)$ & 151 & $(70 \%)$ & 359 & $(60 \%)$ \\
\hline White-collar low skilled & 14 & $(57 \%)$ & 24 & $(67 \%)$ & 24 & $(63 \%)$ & 61 & $(67 \%)$ & 123 & $(65 \%)$ \\
\hline White-collar high skilled & 9 & $(56 \%)$ & 15 & (33\%) & 14 & (64\%) & 102 & (74\%) & 140 & (67\%) \\
\hline Total & 179 & $(56 \%)$ & 229 & $(48 \%)$ & 134 & $(58 \%)$ & 473 & $(70 \%)$ & 1.015 & $(61 \%)$ \\
\hline
\end{tabular}

Table 3: Goodness of fit statistics for diagonal reference models predicting mammography screening.

\begin{tabular}{lclll}
\hline \multirow{2}{*}{ Own ISCO } & Model & Description & AlC & d.f. \\
\cline { 2 - 5 } & A & Baseline model & 1072.7 & 958 \\
\multirow{3}{*}{ Partner's ISCO } & B & Maximisation model & 1076.7 & 957 \\
& & & & \\
& A & Baseline model & 1197.2 & 1009 \\
& B & Maximisation model & 1198.5 & 1008 \\
\hline
\end{tabular}


Table 4: Parameters for diagonal reference model predicting mammography screening — Model A: baseline model.

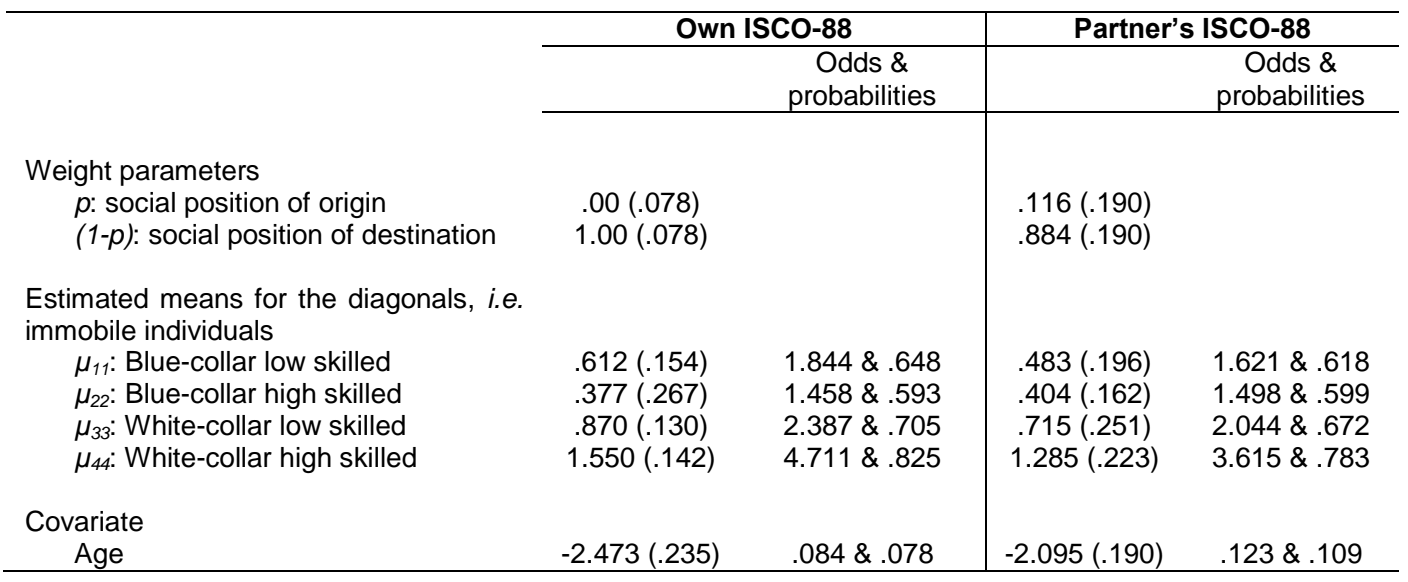

Table 5: Probabilities for mammography screening for mobile and immobile individuals (gray), controlled for age.

\begin{tabular}{|c|c|c|c|c|c|c|c|c|}
\hline & Own & 8 & & & Partr & $\overline{C O-8 \varepsilon}$ & & \\
\hline & Desti & & & & Dest & & & \\
\hline Origin & 1 & 2 & 3 & 4 & 1 & 2 & 3 & 4 \\
\hline 1 & .648 & .593 & .705 & .825 & .618 & .602 & .665 & .764 \\
\hline 2 & .648 & .593 & .705 & .825 & .616 & .600 & .663 & .762 \\
\hline 3 & .648 & .593 & .705 & .825 & .625 & .608 & 672 & .770 \\
\hline 4 & .648 & .593 & .705 & .825 & .638 & .621 & .684 & .783 \\
\hline
\end{tabular}

